\title{
Numerical simulation of hot forging process in production of axisymmetric automobile parts
}

\author{
Hazim Bašić ${ }^{1}$, Mehmed Duharkić ${ }^{2}$, Senad Burak ${ }^{1}$ \\ ${ }^{1}$ University of Sarajevo, Faculty of mechanical en gineering \\ ${ }^{2}$ Cimos TMDAi, subsidiary Novi Travnik,
}

\begin{tabular}{l}
\hline \hline ABSTRACT \\
\hline The fin ite element method were used for the plastic metal flow prediction of ring shaped parts. Various parameters that \\
affect the forging operation are the material characteristics like material strength, ductility, deformation rate, \\
temperature sensitivity and frictional characteristics of the workp iece, preform design, die design and die material. \\
Numerical simulation has been done for axisy mmetric automobile parts. The procedure of nu merical modeling contains \\
all simulations phases like the movement of preform from inductor to the tool, place ment and setting of preform piece \\
inside the tool before the blow in order to get as good result as possible. These techniques are used to reduce the amount \\
of input material for forgings, extend the lifetime of forging dies, and prevent defects in forged components. \\
\hline Keywords: $\quad$ Plastic flow; Hot forging; Finite element method; Numerical simulations \\
Corresponding Author: \\
Hazim Bašić, \\
Mechanical Engineering Faculty \\
University of Sarajevo \\
Vilsonovo šetalište 9, Sarajevo, 71 000, Bosnia and Herzegovina \\
e-mail: basic @ mef.unsa.ba
\end{tabular}

\section{Introduction}

Forging is a widely used technology in the field of material processing using plastic deformation. It is also very important technology of metal parts production for the wide application spectrum. The forgings are ussually the most important and reliable components which are installed in the cars, planes, ships, etc. Automotive mass production systems have increased the demand for forged components. Forging has an advantage because it gives products which have superior mechanical properties with minimum wastage of material [1], [2], [3].

In conventional forging process design, the tool designer must determine the required number of intermediate stages, the preform or intermediate die shape design, the billet dimensions and the process conditions, according to the given final product shape and material. To simulate the metal plastic forming process using a computer becomes a very effective way to improve the scientific basis of forming design. It may provide a means of substituting traditional preform design methods, effectively improving the level of forging-die design and controlling the quality of products through optimization of the process parameters [4, 7-10]. Optimization of the forging processes with numeric simulation has been talked about in numbers of research studies [5, 6, 12-14]. Forging process, usually involve multiple pre-forming processes followed by a specified finishing process. Designing these processes requires that the forging engineers must be possessed high skill and experience in forging process.

The DEFORM software based on the finite element method (FEM) is applied in this research for the analysis of forging process of a ring shaped piece. 


\section{Mathe matical model}

The basic equations of the mechanics of plastic deformation of rigid-plastic and rigid-viscoelastic materials are [1], [4,11]:

- The equilibrium equations:

$$
\frac{\partial \boldsymbol{\sigma}_{i j}}{\partial \boldsymbol{x}_{j}}=0,
$$

Where $\sigma_{i j}(i, j=x, y, z)$ represents the stress tensor with components:

$$
\sigma_{i j}=\left[\begin{array}{ccc}
\sigma_{x} & \tau_{x y} & \tau_{x z} \\
\tau_{y x} & \sigma_{y} & \tau_{y z} \\
\tau_{z x} & \tau_{z y} & \sigma_{z}
\end{array}\right]
$$

- The yield criteria

Criteria of plastic flow can be expressed in the general form:

$$
f\left(\sigma_{i j}\right)=C,
$$

Where $f\left(\sigma_{i j}\right)$ is stress function (yield function), and $C$ is constant.

- The compatibility conditions:

$$
\dot{\varepsilon}_{i j}=\frac{1}{2}\left(\frac{\partial u_{i}}{\partial x_{j}}+\frac{\partial u_{j}}{\partial x_{i}}\right),
$$

Where $\dot{\varepsilon}_{i j}(i, j=x, y, z)$ represents the strain-rate tensor:

$$
\dot{\varepsilon}_{i j}=\left[\begin{array}{ccc}
\dot{\varepsilon}_{x} & \dot{\varepsilon}_{x y} & \dot{\varepsilon}_{x z} \\
\dot{\varepsilon}_{y x} & \dot{\varepsilon}_{y} & \dot{\varepsilon}_{y z} \\
\dot{\varepsilon}_{z x} & \dot{\varepsilon}_{z y} & \dot{\varepsilon}_{z}
\end{array}\right]
$$

The strain-rate tensor components are:

$$
\begin{array}{ll}
\dot{\varepsilon}_{x}=\frac{\partial u_{x}}{\partial x} & \dot{\varepsilon}_{x y}=\frac{1}{2}\left(\frac{\partial u_{x}}{\partial y}+\frac{\partial u_{y}}{\partial x}\right)=\frac{\dot{\gamma}_{x y}}{2} \\
\dot{\varepsilon}_{x}=\frac{\partial u_{y}}{\partial y} & \dot{\varepsilon}_{y z}=\frac{1}{2}\left(\frac{\partial u_{y}}{\partial z}+\frac{\partial u_{z}}{\partial y}\right)=\frac{\dot{\gamma}_{y z}}{2} \\
\dot{\varepsilon}_{z}=\frac{\partial u_{z}}{\partial z} & \dot{\varepsilon}_{z x}=\frac{1}{2}\left(\frac{\partial u_{z}}{\partial x}+\frac{\partial u_{x}}{\partial z}\right)=\frac{\dot{\gamma}_{z x}}{2}
\end{array}
$$

where $u_{i}(i=x, y, z)$ are velocity vector components.

- The constitutive relation:

Where:

$$
\dot{\varepsilon}_{i j}=\frac{3}{2} \frac{\dot{\bar{\varepsilon}}}{\bar{\sigma}} \sigma^{\prime}{ }_{i j}
$$

$$
\bar{\sigma}=\sqrt{\frac{3}{2}}\left(\sigma_{i j}^{\prime} \sigma_{i j}^{\prime}\right)^{\frac{1}{2}}=\bar{\sigma}(\bar{\varepsilon}, \dot{\bar{\varepsilon}}),
$$

is the effective stress, 


$$
\dot{\bar{\varepsilon}}=\sqrt{\frac{2}{3}}\left(\dot{\varepsilon}_{i j} \dot{\varepsilon}_{i j}\right)^{\frac{1}{2}}
$$

is effective strain rate and $\sigma^{\prime}{ }_{i j}$ is deviatoric stress tensor:

$$
\sigma_{i j}^{\prime}=\left[\begin{array}{ccc}
\sigma_{x}-\sigma & \sigma_{x y} & \sigma_{x z} \\
\sigma_{y x} & \sigma_{y-\sigma} & \sigma_{y z} \\
\sigma_{z x} & \sigma_{z y} & \sigma_{z}-\sigma
\end{array}\right]
$$

For the heat transfer analysis, the energy balance equation is used:

$$
\kappa_{1} T,{ }_{i i}+\dot{r}-\rho c \dot{T}=0
$$

Where $\kappa_{1} T_{i i}$ is the heat transfer rate, $\kappa_{1}$ denotes thermal conductivity, $\dot{r}$ is the heat generation rate, and $\rho c \dot{T}$ is the internal energy-rate. The notation $T_{, i i}$ is used for denoting differentiation and repeated subscript meaning summation.

\section{The technology of ring-shaped part hot forging}

Material used for numerical simulation is AISI 310. This material is austenitic stainless steel and based on forging pressure and loads requirements is more difficult to forge than carbon or low-alloys steels. Chemical composition of AISI 310 is given in the Table 1 [15]. This material meet the requirements of functioning on high temperature.

Table 1. Chemical composition of AISI 310

\begin{tabular}{|c|c|c|c|c|c|c|c|c|}
\hline \multicolumn{2}{|c|}{ Element } & C & Mn & P & S & Si & Cr & Ni \\
\hline \multirow{2}{*}{ Content, \% } & Min & - & - & - & - & - & 24,00 & 19,00 \\
\cline { 2 - 9 } & Max & 0,25 & 2,00 & 0,045 & 0,030 & 1,50 & 26,00 & 22,00 \\
\hline
\end{tabular}

The mechanical properties at room temperature of grade AISI 310 steel are as follows:

- Tensile strength $-\min 515 \mathrm{MPa}$

- Yield strength - min $205 \mathrm{MPa}$

- Elongation - $\min 40 \%$

- Hardness - max $217 \mathrm{HB}$.

In hot forging, the effect of temperature on the process is significant. The workpiece must be heated in an oven and then transferred to the forming machine. A coupled thermal and mechanical numerical analysis with large strain theory is therefore necessary.

The final shape of forging part is given in Figure 2.

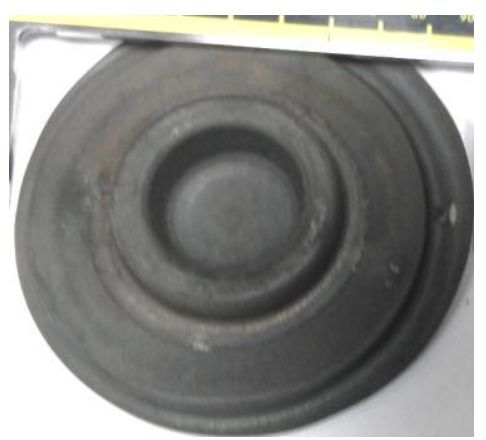

Figure 2. Shape of the forging part after the final forging 
Numerical simulation of the forging process is performed for every operation given in Table 2.

Table 2. Technology steps of hot forging

\begin{tabular}{|c|l|l|c|}
\hline $\begin{array}{c}\text { Step } \\
\text { Number }\end{array}$ & \multicolumn{1}{|c|}{ Activity } & \multicolumn{1}{|c|}{$\begin{array}{c}\text { Type of time } \\
\text { spend }\end{array}$} & $\begin{array}{c}\text { Duration } \\
(\mathrm{sec} .)\end{array}$ \\
\hline 1. & $\begin{array}{l}\text { Transport of the preform from the inductor for } \\
\text { heating preforms to the first tool }\end{array}$ & Transport time & $4 \mathrm{sec.}$ \\
\hline 2. & Preform standby on the compression tool & Standby period & $1.5 \mathrm{sec}$. \\
\hline 3. & Phase 1 - compression & Forging time & \\
\hline 4. & $\begin{array}{l}\text { Transport of the preform from the compression tool } \\
\text { to the pre-forging tool }\end{array}$ & Transport time & $2.5 \mathrm{sec}$. \\
\hline 5. & Preform standby on the pre-forging tool & Standby period & $1.5 \mathrm{sec}$. \\
\hline 6. & Phase 2 - pre-forging & Forging time & \\
\hline 7. & $\begin{array}{l}\text { Transport of preform from the pre-forging tool to the } \\
\text { finish forging tool }\end{array}$ & Transport time & $2.5 \mathrm{sec.}$ \\
\hline 8. & Preform standby on the finish forging tool & Standby period & $1.5 \mathrm{sec.}$ \\
\hline 9. & Phase 3 - finish forging & Forging time & \\
\hline
\end{tabular}

Layout of forging tools is given in Figure 1, while the final shape of forging part after last forging phase is shown in Figure 2.

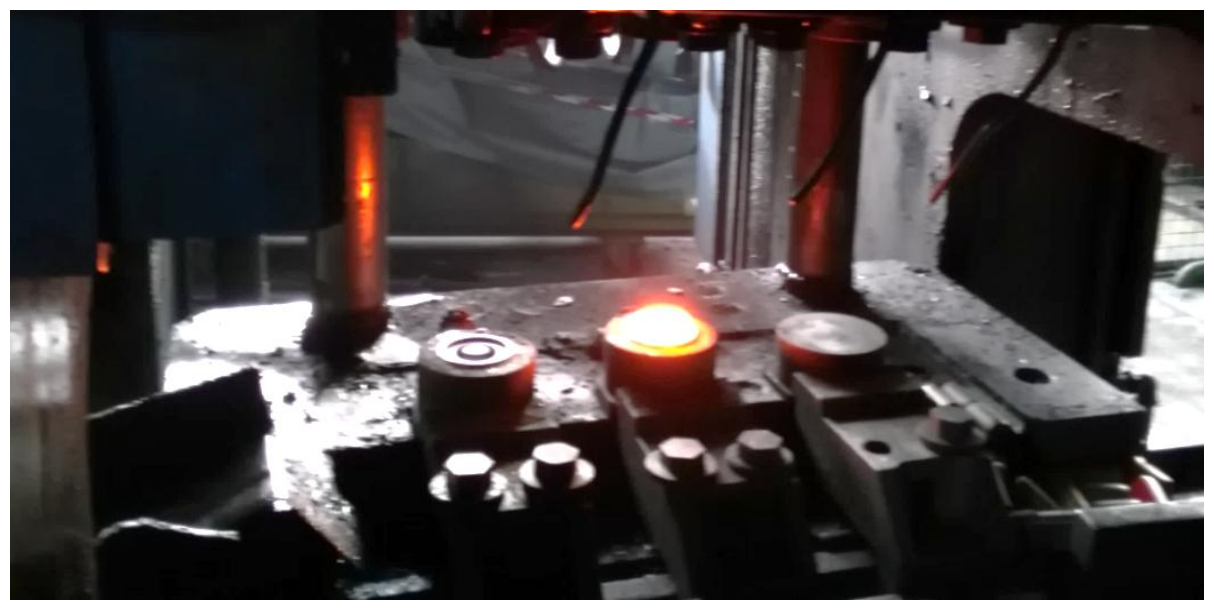

Figure 1. Layout of forging tools

Friction is one of the largest sources of error and uncertainty in the mode ling of metal forming operations. The problem usually reduces by introducing a friction coefficient or friction factor under true forming conditions (including strain rates, dis placements rates, pressure, surface roughness, lubricant quantities and conditions, local temperature, and so on). 
In the metal forming simulations usually two friction formulations are used: Coulomb-s frictions law (also known as Amonton's law) and the constant friction law (Tresca friction), [1, 9, 11]. In the numerical simulation in this work the constant friction law was used with coefficient 0.3 .

\section{Nume rical simulation of axis ymme tric forging}

The basic input data for the numerical simulation are:

- The mechanical and physical characteristics of forging material,

- Tool geometry,

- Friction conditions and

- technology parameters.

Technology parameters are temperature of forging part and ram velocity.

The numerical calculation procedure includes all the steps that have been taken into account, among other, the phase of workpiece transport from the inductor to the tool, standby phase of the preform in the tool before the blow.

Due to simplification and calculation time saving, the calculation has been performed on $1 / 4$ axisymmetric forging preform with dimensions $\varnothing 35 \times$ x 41.5, shown in Figure 3. The generated numerical grid cons ists of 50.336 elements. Boundary condition of plane symmetry was used on both of the symmetry planes. On the free surfaces the boundary conditions for heat exchange with the environment are specified.
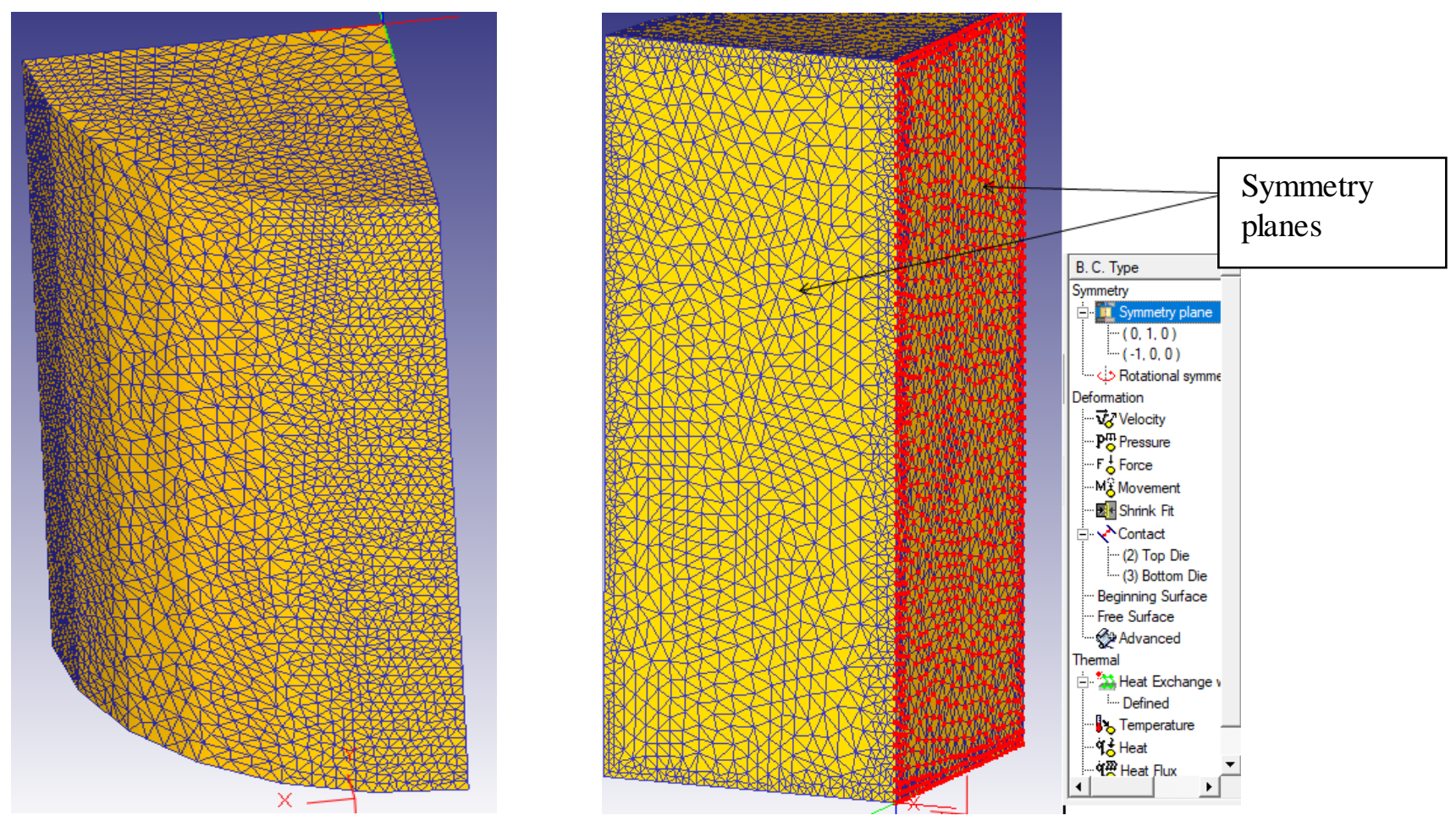

Figure 3. Numerical mesh and symmetry planes definition

The workpiece position in compression toll (Phase 1) is given in Figure 8(a). Numerical simulation gave the temperature distribution of workpiece after the transport time from inductor to the compresson tool, Figure 
4(b). The temperature filed after stand-by time of workpiece on the compression tool is given in Figure 4(b), where the temperature range is between $1000{ }^{\circ} \mathrm{C}$ and $1150{ }^{\circ} \mathrm{C}$. The initial temperature of built was $1150{ }^{\circ} \mathrm{C}$.

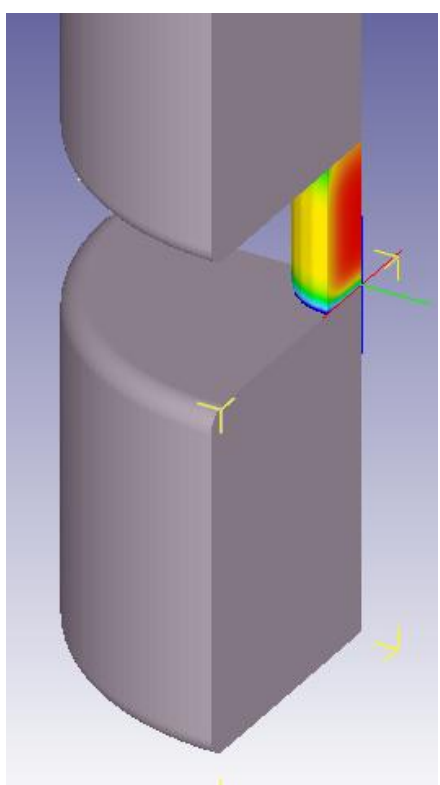

(a)

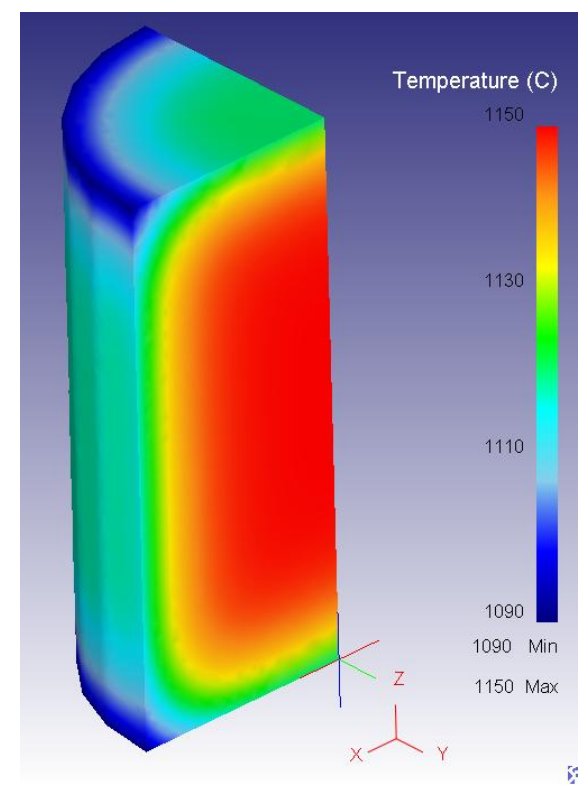

(b)

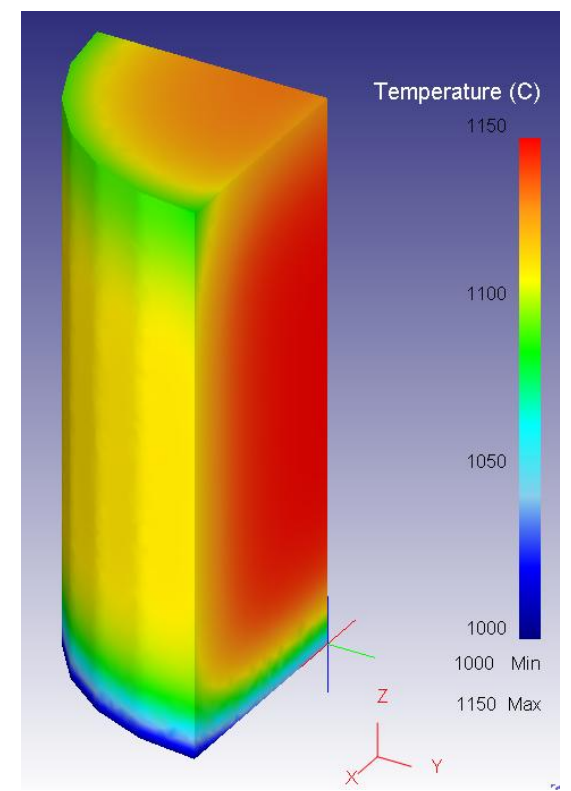

(c)

Figure 4. The starting point of compression and temperature distributions, (a) workpiece position, (b) temperature field after transport to compression tool, (c) temperature distribution after stand-by time

Schematic of the shape change during compression process (Phase 1) is shown on Figure 5(a), and the shape of workpiece and the streamlines on the end step of forging phase 1 on Figure 5(b). The fiber flow given on the Figure 5(b) shows that material flowing in expected direction and it is in good correlation with real forging.

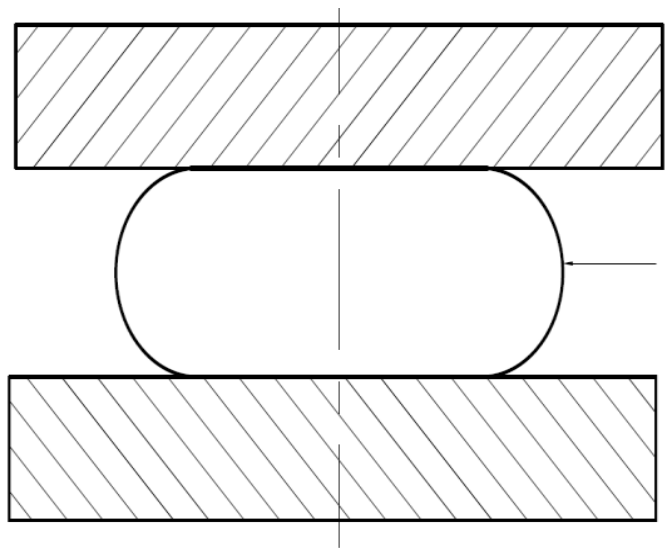

(a)

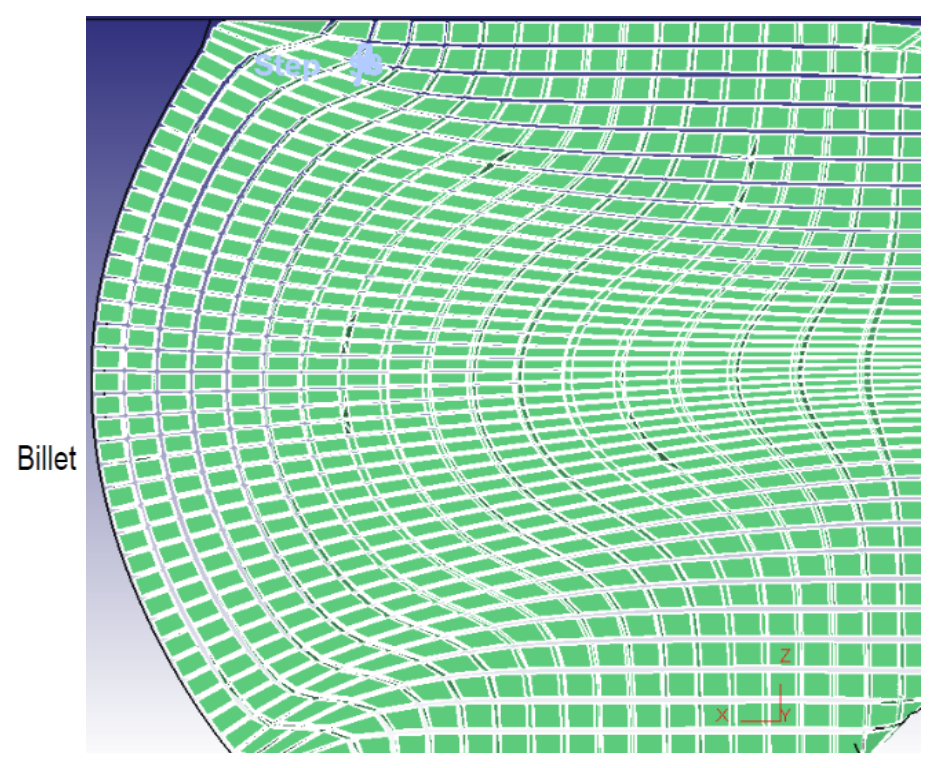

(b)

Figure 5. The shape change during compression process (a) and fiber flow of phase 1 (b) 
The shape of forging after Phase 1 and the load prediction for this step of forging is given in Figure 6, and it is shows good agreement with experimental data.
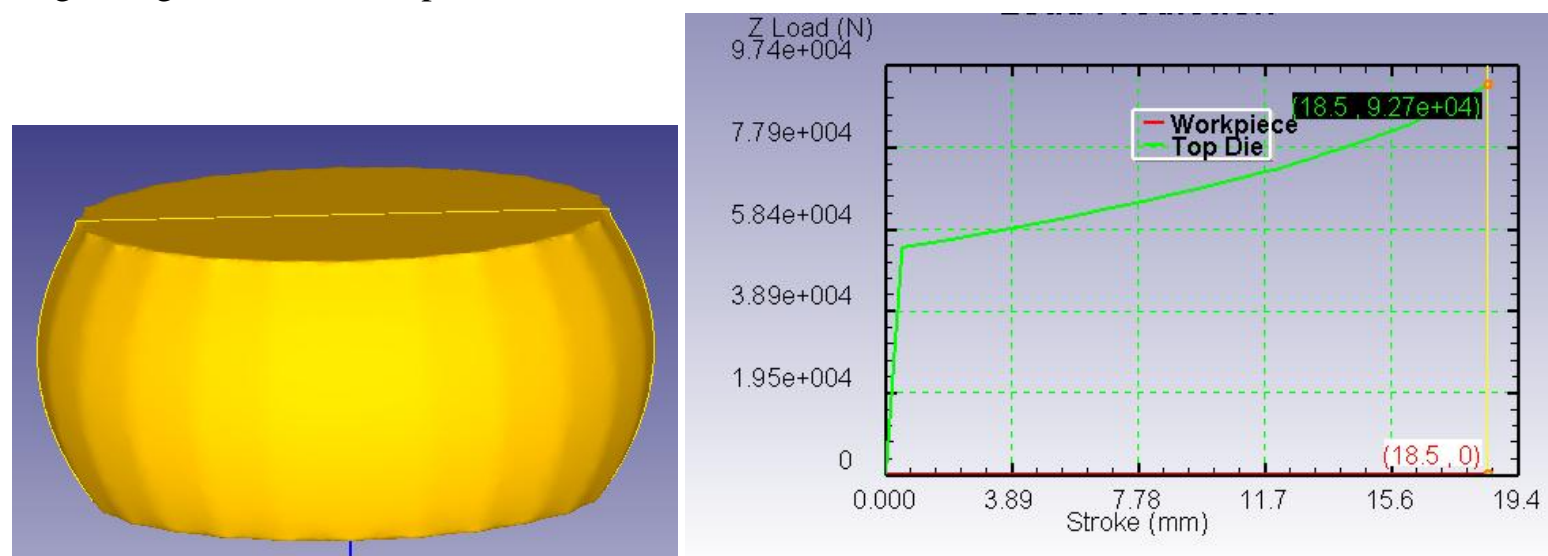

Figure 6. Load prediction diagram for Phase 1 (compression)

The workpiece position in pre-forging toll (Phase 1) is given in Figure 7(a), and the shape of workpiece after numerical simulation in Figure 7(b).

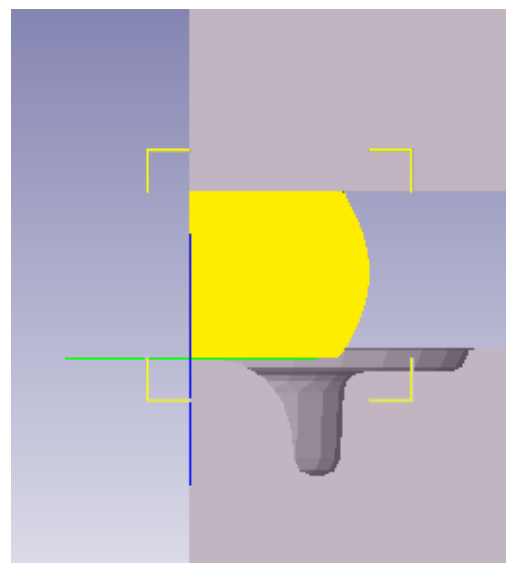

(a)

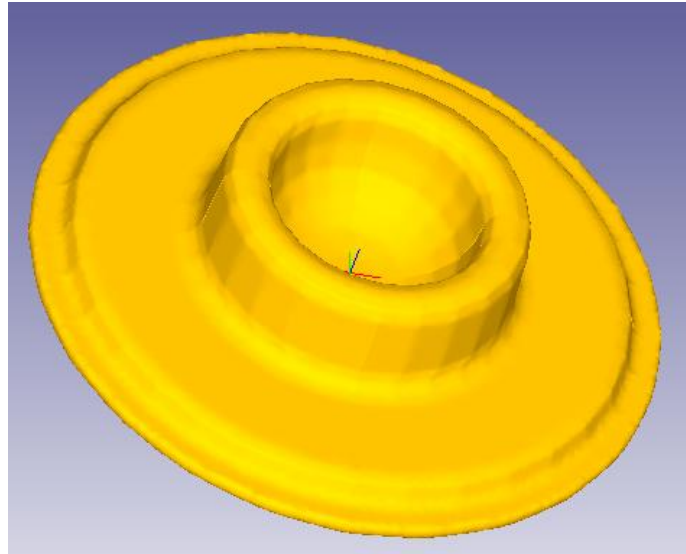

(b)

Figure 7. Pre-forging phase, (a) workpiece position, (b) shape of workpiece

Numerical simulation gave the load prediction diagram for pre-forging that is given in Fkigure 8, and which is in good correlation with experimental data.

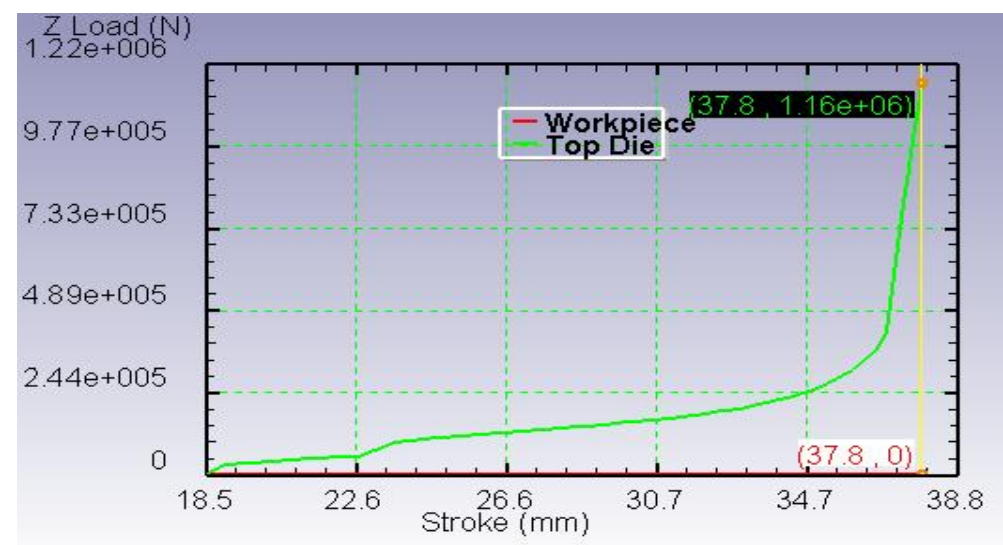

Figure 8. Load prediction diagram for Phase 2 (pre-forging) 
The temperature distribution after the transport time to the Phase $3(2.5 \mathrm{sec}$.) is given in the Figure 9(a), and the temperature filed after stand-by time $(1.5 \mathrm{sec}$.), Figure $9(\mathrm{~b})$. The calculated and experimentally obtained average workpiece temperature are in good agreement.

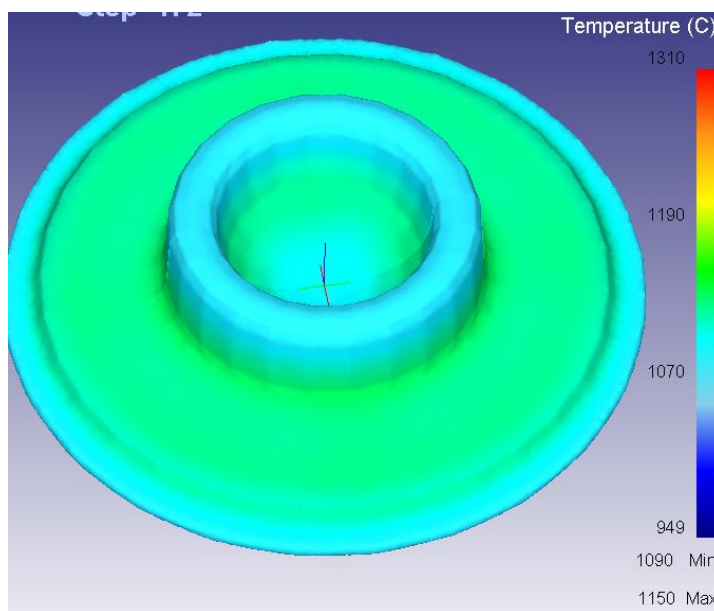

(a)

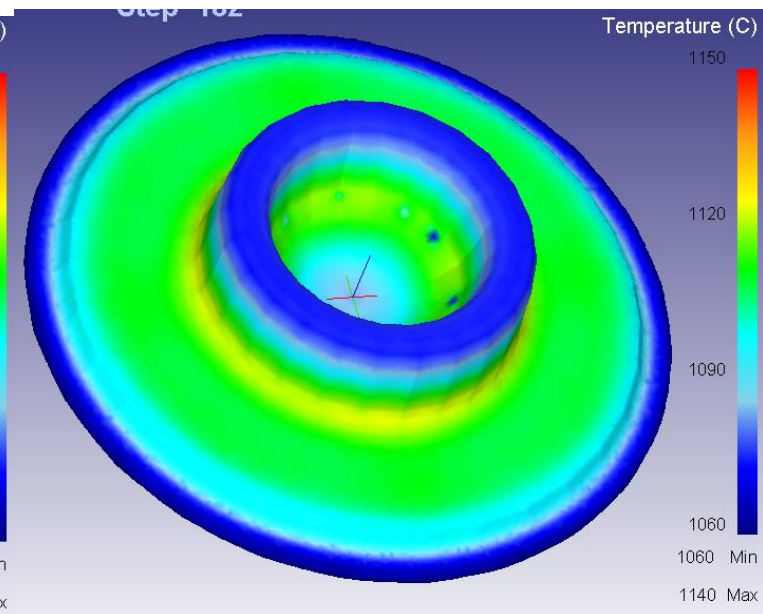

(b)

Figure 9. Temperature distributions, (a) temperature field after transport to compression tool, (c) temperature distribution after stand-by time

The shape of workpiece after final forging, Figure 10(a), shows correct die filing. The load prediction diagram for this step of forging is given in Figrue 10(b). Load prediction is in good agreement with real data (the experimental force was measured directly on the press).
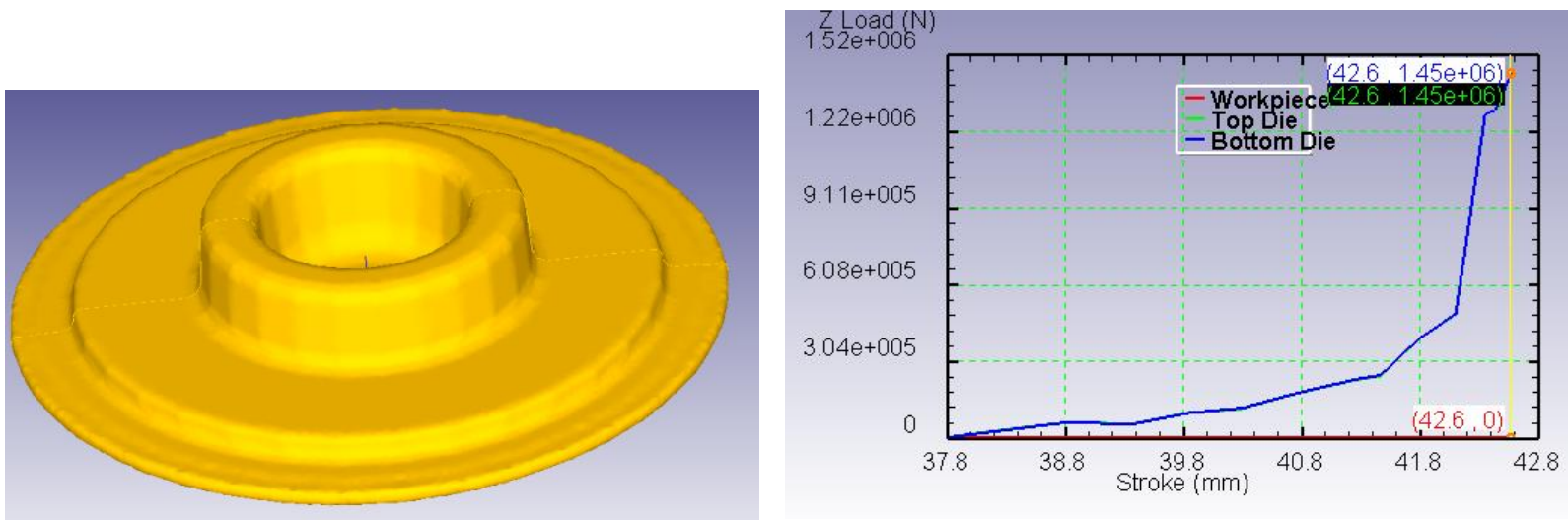

Figure 10. Final forging results, (a) the workpiece shape, (b) the load prediction diagram Data of complete numerical simulation, including all of considering forging steps are given in Table 3 . The minimum and maximum size of finite elements during all calculation was between $0.3 \mathrm{~mm}$ to $1.2 \mathrm{~mm}$.

Table 3. Parameters of numerical simulations for all forging steps

\begin{tabular}{|c|l|c|c|c|}
\hline $\begin{array}{l}\text { Step } \\
\text { Number }\end{array}$ & \multicolumn{1}{|c|}{ Activity } & $\begin{array}{c}\text { No. of time } \\
\text { steps }\end{array}$ & $\begin{array}{c}\text { Step } \\
\text { duration }\end{array}$ & $\begin{array}{c}\text { Number of } \\
\text { finite } \\
\text { elements }\end{array}$ \\
\hline 1. & $\begin{array}{l}\text { Transport of the preform from the inductor } \\
\text { for heating preforms to the first tool }\end{array}$ & 40 & $0.1 \mathrm{~s}$ & 50336 \\
\hline 2. & Preform standby on the compression tool & 15 & $0.1 \mathrm{~s}$ & 50336 \\
\hline
\end{tabular}




\begin{tabular}{|c|l|c|c|c|}
\hline $\begin{array}{c}\text { Step } \\
\text { Number }\end{array}$ & \multicolumn{1}{|c|}{ Activity } & $\begin{array}{c}\text { No. of time } \\
\text { steps }\end{array}$ & $\begin{array}{c}\text { Step } \\
\text { duration }\end{array}$ & $\begin{array}{c}\text { Number of } \\
\text { finite } \\
\text { elements }\end{array}$ \\
\hline 3. & Phase 1 - compression & 37 & $0.5 \mathrm{~mm}$ & 50336 \\
\hline 4. & $\begin{array}{l}\text { Transport of the preform from the } \\
\text { compression tool to the pre-forging tool }\end{array}$ & 10 & $0.25 \mathrm{~s}$ & 43548 \\
\hline 5. & Preform standby on the pre-forging tool & 10 & $0.15 \mathrm{~s}$ & 43548 \\
\hline 6. & Phase 2 - pre-forging & 78 & $0.4825 \mathrm{~mm}$ & 43548 \\
\hline 7. & $\begin{array}{l}\text { Transport of preform from the pre-forging } \\
\text { tool to the finish forging tool }\end{array}$ & 10 & $0.25 \mathrm{~s}$ & 69660 \\
\hline 8. & Preform standby on the finish forging tool & 10 & $0.15 \mathrm{~s}$ & 69660 \\
\hline 9. & Phase 3 - finish forging & 14 & $0.46 \mathrm{~mm}$ & 69660 \\
\hline
\end{tabular}

\section{Conclusion}

The field of optimization and numerical simulation of forming process includes almost every aspect of technology. It includes the optimum die design, preform design and the process parameters. This results in manufacturing with reduced defects and minimum forging load. Numerical calculation for axisymmetric forging is performed in 9 sequences which correspond to the realistic process of production. The justifiable usage of the numerical simulation for the analys is of plastic metal flow which leads to a faster development of the new products is shown. It allows the simulation of various things like the tool and workpiece temperatures, the heat transfer during deformation, strain-rate dependent material properties, strain hardening characteristics and capabilities for microstructure analysis. It is obvious that numerical simulation is not all mighty but is just one of useful tools for design engineers. No matter what the tools have good capabilities, they are useful only when they are properly used. Misunderstanding about FEA simulation often leads fail of its practical use. Anlysis of results of numerical simulation of hot forging process showed good correlation with the practical situations. The numerically obtained results demonstrate forging without cracks, material overlapping and with good die filling, like in the practice.

\section{References}

[1] Kobayasi S., OH S-I., Altan T., Metal Forming and Finite - Element Method. New York Oxford. Oxford University press, 1989.

[2] Kim, H, Yagi, T., Yamanaka, M., FE simulation as a must tool in cold/warm forging process and tool design, Journal of Materials Processing Technology, Vol. 98, pp. 143-149, 2000.

[3] Fujikawa S., Application of CAE for hot-forging of automotive components, Journal of Materials Processing Technology, Vol. 98, pp. 176-181, 2000.

[4] Chenot J.-L., Bouchard P.-O., Fourment L., Lasne P., Numerical Simulation and Optimization of the Forging Process, International Cold Forging Congress - 12th ICFC 2011, Stutgart, Germany, 2011.

[5] Bašić H., Demirdžić I., Muzaferija S., "Finite volume method for simulation of extrusion processes", 
Int. J. Numer. Meth. in Engng., Wiley InterScience, Vol. 62:475-494, 2005.

[6] Kaur, J., Pabla, B.S., Dhami, S.S., A Review on Field Areas of Research in Forging Process using FEA, International Journal of Engineering Research \& Technology (IJERT), Vol. 5(01), pp. 383-393, 2016.

[7] Lee, Y, Lee, J., Ishikawa, T., Analys is of the elastic characteristics at forging die for the cold forged dimensional accuracy, Journal of Materials Processing Technology, 130-131, pp. 532-539, 2002.

[8] Bašić H., 'The friction models integration in calculation of bulk metal forming technologies by finite volume method', Journal of Trends in the Development of Machinery and Associated Technology, Vol. 17, No. 1, 2013.

[9] Bašić H., "Friction models comparison in finite volume method simulation of bulk metal forming technologies", Journalfor Technology of Plasticity, Vol. 33,1-2, pp. 113-123, 2008.

[10] Kakimotoa H., Arikawab T., Prediction of surface crack in hot forging by numerical simulation. 11th International Conference on Technology of Plasticity, ICTP 2014, 19-24 October 2014.

[11] Liu G., Zhang L.B., Hua X.L.,Wang Z.R., Wang R.W., Huang S.D.,Tang Q.B., Applications of numerical simulation to the analysis of bulk-forming processes-case studies. Journal of Materials Processing Technology 150, pp. 56-61, 2004.

[12] Choi, J.C, Choi, Y., Precision forging of spur gears with inside relief, International Journal of Machine Tools \& Manufacture, 39, pp. 1575-1588, 1999.

[13] Scahaeffer L., Brito A. M. G., Geier M., 2005. Numerical Simulation using Finite Elements to Develop and Optimize Forging Processes. Steel research int., 76, No 2/3, pp. 199-204, 2005.

[14] Zhang C., Li L., Zheng Z., Numerical Simulation of Forging Process for Steam Turbine Blade. International Journal of Mechanical \& Mechatronics Engineering IJMME-IJENS Vol. 17(03), 2017.

[15] https://www.nickelinstitute.org/ /media/Files/TechnicalLiterature/High_TemperatureCharacteristicsof StainlessSteel_9004_.ashx; $(30.05 .2018$. 